\title{
MTHFR Gene Mutation and Its Repercussion in the Genesis and Treatment of Depression: Case Report
}

\author{
Alexandre L Laux ${ }^{1}$, Alana C Klochinski ${ }^{2}$, Bruna F Bobato², Evelyn C S Dib ${ }^{2}$, Harien A Sprung ${ }^{2}$, \\ Jussara R Mallmann ${ }^{2}$, Vitoria L G Rota ${ }^{2}$ \\ 1 - Psychiatrist and professor at Faculdades Pequeno Príncipe - Curitiba-PR \\ 2 - Medical students from Faculdades Pequeno Príncipe - Curitiba-PR
}

\begin{abstract}
This study aims to report the correlation of MTHFR gene mutation with the genesis of depression and antidepressants non-response in a patient, highlighting the importance of genetic investigation and indicating the replacement of L-methylfolate as an effective treatment adjuvant. This is a case report of a patient diagnosed with major depressive disorder, refractory to pharmacological therapies, in monotherapy or combination therapy, and psychotherapy. After 1 year and 4 months of persistent residual symptoms, genetic testing of the MTHFR gene was requested with confirmation of a heterozygous double mutation of MTHFR. This gene polymorphism can result in deficiency of L-methylfolate, which is related to psychiatric diseases and refractoriness to antidepressant therapy. With the introduction of 1-methylfolate $15 \mathrm{mg}$, the patient reported remission of depressive symptoms in 4 months of follow-up. MTHFR gene mutations influence the action of folate, favoring depression and leading to refractory response to conventional treatment.
\end{abstract}

Keywords: Depressive Disorder; Treatment-Resistant; Folic acid-therapeutic use; Methylenetetra hydrofolate Reductase (NADPH2); Methylation; Biopterin/metabolism.

\section{Introduction:}

Several studies show genetic influence on depression. One of the genes involved in unipolar depression is MTHFR, which encodes the enzyme methylenetetrahydrofolate reductase (MTHFR). ${ }^{1}$ Located at the end of the short arm of chromosome 1 (1p36.3), containing 11 exons and at least 65 documented variants, it plays a central role in folate metabolism. ${ }^{2,3}$ MTHFR enzyme catalyzes the conversion of 5-10methylenetetrahydrofolate to 5-methyltetrahydrofolate, or L-methylfolate (active form of folate) which, in its turn, is a substrate for converting homocysteine to methionine. ${ }^{4}$ Methionine is converted into a methyldonor, S-adenosylmethionine (AdoMet, SAM), which is used for the methylation of DNA and proteins. Lmethylfolate is also an important regulator of a crucial cofactor for the synthesis of monoamines, tetrahydrobiopterin (BH4). The enzymes requiring $\mathrm{BH} 4$ as a cofactor are both tryptophan hydroxylase, the rate-limiting enzyme in the synthesis of serotonin, and tyrosine hydroxylase, which is the rate-limiting enzyme in the synthesis of dopamine and noradrenaline. ${ }^{3,5}$ Thus, the importance of MTHFR in the synthesis of folate and in the epigenetics of the regulation of monoamine levels can be noticed. 


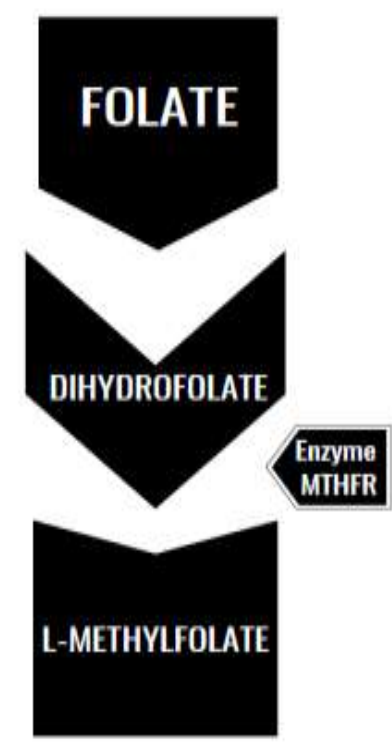

\section{Figure 1 - Conversion of folate into L-methylfolate}

The prevalence of MTHFR polymorphism is unknown, varying according to the worldwide distribution. Numerous studies have found a high incidence of mutations in this gene in patients with major depressive disorder, especially in those refractory to treatment with selective serotonin reuptake inhibitors (SSRIs). ${ }^{2,3}$ This gene allele frequencies vary greatly within different ethnic groups, with more than 20 haplotypes differently present in Caucasian, African American, Hispanic or Latin (Mexican), and Asian people. The two most common MTHFR gene mutations are found in the C677T and A1298C alleles. ${ }^{4}$ The transition of C677 allele from $\mathrm{C}$ to $\mathrm{T}$ is prevalent: it leads to reduced enzyme activity, impaired methylation and, consequently, high levels of plasma total homocysteine, as well as folate deficiency. ${ }^{6}$

\section{Chromosome 1}

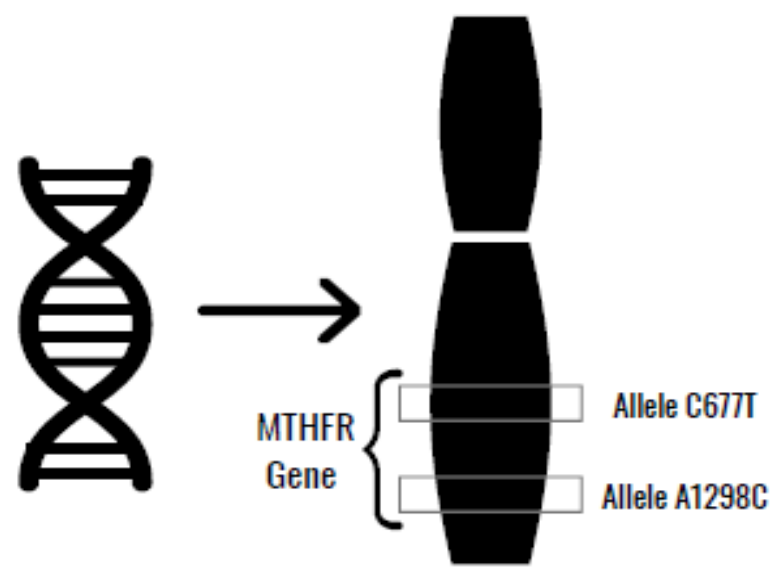

Figure 2 - Location of MTHFR gene

Besides being a cofactor for the synthesis of serotonin, dopamine, and noradrenaline (tryptophan hydroxylase and tyrosine hydroxylase, respectively), folate is also involved in the methylation of genes and enzymes - it is responsible for the "silencing" of the enzyme Catechol O-Methyltransferase (COMT), which degrades dopamine and noradrenaline. ${ }^{3}$ Therefore, folate is important for maintaining serotonin, dopamine, and noradrenaline levels, and its low serum level may delay the response to treatment with antidepressants.

We still find discussions about whether MTHFR polymorphism is an independent factor or an additional risk factor for specific psychiatric symptoms; however, it is known that in addition to major depressive disorder, MTHFR gene mutations are associated with other psychiatric disorders, such as schizophrenia, autism, and bipolar disorder - especially the C677T variant - as well as to decreased general mental health status and greater reactivity to stress. ${ }^{2,3,7}$ There is also a correlation with other pathologies, neural tube 
defects, and cardiovascular diseases, since polymorphisms $677 \mathrm{C}>\mathrm{T}$ and $1298 \mathrm{~A}>\mathrm{C}$ can affect the homocysteine level to varying degrees. ${ }^{3,4,6,7}$

The objective of this study is to report the correlation of MTHFR gene mutation with the genesis of depression and refractoriness to treatment with antidepressants in a patient, thus highlighting the importance of genetic investigation in the depression that is refractory to antidepressant therapy, indicating the replacement of L-methylfolate as an effective treatment alternative in these cases.

\section{Case Report:}

Thirty-two-year-old male patient at the beginning of treatment (12/2016), single, without children, environmental engineer. He has been on psychiatric treatment for 2 years and 8 months, reporting that he has never been a "happy" person, but that in the year before he started his treatment, he had noticed a worsening of his condition, describing depressive manifestations with a predominance of apathetic-anergic symptoms.

At the first consultation, the patient complained of discouragement, anhedonia, self-isolating tendency, professional dissatisfaction, and decreased self-confidence, showing hypothymia and anergy at the mental state examination.

Approximately 6 months before the current follow-up, the patient had already sought psychiatric treatment with another professional, when he was prescribed desvenlafaxine $50 \mathrm{mg}$, then fluvoxamine $50 \mathrm{mg}$ and, lastly, escitalopram $10 \mathrm{mg}$, but with abandonment of treatment due to side effects ("I felt my pupils dilating", when reporting on desvenlafaxine). The patient has a history of previous bariatric sleeve surgery in 2014.

At the first visit, he was diagnosed with a major depressive episode, and the antidepressant bupropion 150 mg was introduced due to the profile of symptoms. Complementary laboratory tests (table 1), which were within normal limits, were requested to rule out differential diagnoses.

Table 1 - Laboratory tests: first consultation (12/2016)

\begin{tabular}{|l|c|c|}
\hline \multicolumn{1}{|c|}{ EXAMS } & RESULTS & RANGE VALUES* \\
\hline Total Cholesterol & 143 & $<190 \mathrm{mg} / \mathrm{dL}$ \\
\hline HDL & 52 & $>40 \mathrm{mg} / \mathrm{dL}$ \\
\hline LDL & 79 & $<100 \mathrm{mg} / \mathrm{dL}$ \\
\hline TG & 59 & $<150 \mathrm{mg} / \mathrm{ml}$ \\
\hline ALT & 22 & $<41.0 \mathrm{U} / \mathrm{L}$ \\
\hline AST & 30 & $<40.0 \mathrm{U} / \mathrm{L}$ \\
\hline Gama GT & 9 & 0.70 to $61.0 \mathrm{U} / \mathrm{L}$ \\
\hline Free T4 & $1.14 \mathrm{ng} / \mathrm{dL}$ \\
\hline TSH & 1.51 & 0.35 to $4.94 \mu \mathrm{IU} / \mathrm{ml}$ \\
\hline Uric acid & 5.1 & 2.5 to $7.5 \mathrm{mg} / \mathrm{dL}$ \\
\hline Transferrin & 246 & 200 to $360 \mathrm{mg} / \mathrm{dL}$ \\
\hline Vitamin B12 & 421 & 187.0 to $883.0 \mathrm{pg} / \mathrm{ml}$ \\
\hline Folic acid & 14.4 & $>4 \mathrm{ng} / \mathrm{ml}$ \\
\hline Calcium & 9.2 & 8.40 to $10.20 \mathrm{mg} / \mathrm{dL}$ \\
\hline Fasting glycemia & 86 & 65.0 to $99.0 \mathrm{mg} / \mathrm{dL}$ \\
\hline Total proteins & 7.0 & 6.0 to $8.0 \mathrm{~g} / \mathrm{dL}$ \\
\hline Albumin & 4.5 & 3.5 to $5.5 \mathrm{~g} / \mathrm{dL}$ \\
\hline Globulin & 2.5 & 1.5 to $3.5 \mathrm{~g} / \mathrm{dL}$ \\
\hline Vitamin D & 37 & $>20.0 \mathrm{ng} / \mathrm{ml}$ \\
\hline Zinc & 93.1 & 70.0 to $120.0 \mu \mathrm{g} / \mathrm{dL}$ \\
\hline Ferritin & 168 & 21.81 to $274.66 \mathrm{ng} / \mathrm{mL}$ \\
\hline Serum iron & 117 & 59.0 to $158.0 \mu \mathrm{g} / \mathrm{dL}$ \\
\hline Glycated Hemoglobin & $5.1 \%$ & $<5.7 \%$ \\
\hline Postprandial glycemia & 66 & - \\
\hline
\end{tabular}

*According to the reference laboratory 
In the following consultations (during the first 3 months), bupropion titration up to $450 \mathrm{mg}$ was performed. When the target dose was reached, the patient showed transient side effects, such as nausea, irritability, insomnia, and worsening of mood, but with an overall improvement of $75 \%$ of his symptoms - his residual complaints were lack of initiative, inattention, and affective indifference.

Due to residual complaints, treatment potentiation was attempted in the 2 subsequent months with modafinil $100 \mathrm{mg}$ and, subsequently, lisdexamfetamine $30 \mathrm{mg}$. With the former, he reported initially having drowsiness and then maintenance of his residual complaints; with the latter, despite getting adapted, he denied any benefits regarding the residual symptoms.

In view of the condition progression and the adaptation to therapies, the adjustment of bupropion to $600 \mathrm{~m} /$ day was made, in agreement with the patient; after 1 month taking this dosage, he reported an improvement of $80 \%$ of his condition, and kept the report of residual lack of initiative.

In the 3 subsequent months, further therapy potentiation was attempted, first with vortioxetine and then with agomelatine, both in full dose, but again the patient did not show any clinical benefit. However, in this period, the patient's mother died, which impacted negatively on the therapeutic evaluation.

Due to the lack of response of residual symptoms, the patient was referred to another professional for assessment of the possible benefits of transcranial magnetic stimulation, but the patient did not present for evaluation.

The prescription of bupropion $600 \mathrm{mg}$ was maintained, associated with guidelines for behavioral activation, and psychotherapy for 1 year and 4 months, with residual symptoms of lack of initiative and pleasure persisting.

Routine complementary laboratory tests were requested (table 2) and this time the genetic test of the MTHFR gene was included (table 3).

Table 2 - Follow-up laboratory tests (03/2019)

\begin{tabular}{|c|c|c|}
\hline TESTS & RESULTS & RANGE VALUES* \\
\hline Blood glucose & 91 & 65.0 to $99.0 \mathrm{mg} / \mathrm{dL}$ \\
\hline Urea & 26 & 16.6 to $48.5 \mathrm{mg} / \mathrm{dL}$ \\
\hline Creatinine & 1.02 & $>90 \mathrm{ml} / \mathrm{min} / 1.73 \mathrm{~m}^{2}$ \\
\hline ALT & 21 & Men: $<41.0 \mathrm{U} / \mathrm{L}$ \\
\hline AST & 15 & Men $:<40.0 \mathrm{U} / \mathrm{L}$ \\
\hline Gamma GT & 14 & Men: 8.0 to $61.0 \mathrm{U} / \mathrm{L}$ \\
\hline Total Cholesterol & 170 & $<190 \mathrm{mg} / \mathrm{dL}$ \\
\hline HDL & 44 & $>40 \mathrm{mg} / \mathrm{dL}$ \\
\hline Dosed LDL & 115 & $<130 \mathrm{mg} / \mathrm{dL}$ \\
\hline Triglycerides & 151 & Fasting: $<150 \mathrm{mg} / \mathrm{ml}$ \\
\hline Vitamin B12 & 640.3 & 187.0 to $883.0 \mathrm{pg} / \mathrm{ml}$ \\
\hline Folic acid & $>20$ & $\geq 4.00 \mathrm{ng} / \mathrm{ml}$ \\
\hline Free T4 & 1.15 & 0.70 to $1.48 \mathrm{ng} / \mathrm{dL}$ \\
\hline TSH & 2.23 & 0.35 to $4.94 \mu I U / m l$ \\
\hline Homocysteine & 10.5 & 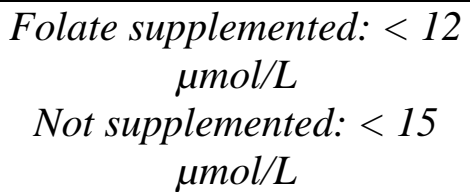 \\
\hline
\end{tabular}

*According to reference laboratory

As a potentiation proposal, on the day exams were requested, methylfolate was already introduced, which was gradually adjusted to the dose of $15 \mathrm{mg}$. 
Approximately 2 months after the last consultation, the patient returned with normal routine complementary exams, but with a double heterozygous mutation of the MTHFR gene (mutation C677T in heterozygosis and A1298C mutation in heterozygosis), which leads to a 50\% reduction of enzyme activity.

Table 3 - Genetic test for MTHFR gene mutation (04/2019)

\begin{tabular}{|c|c|}
\hline TESTS & RESULTS \\
\hline Mutation C677T & Heterozygous \\
\hline Mutation A1298C & Heterozygous \\
\hline & $\begin{array}{c}50 \% \text { reduction of enzyme } \\
\text { activity }\end{array}$ \\
\hline
\end{tabular}

As for the response, the patient reported having significant improvement in residual symptoms (reduction of lack of initiative and pleasure) - "less than $10 \%$ before I get back to normal" - which motivated the maintenance of the treatment with methylfolate $15 \mathrm{mg}$ daily.

After 4 months on medication, the patient returned reporting remission of depressive symptoms, with only reactive mood when facing difficult paternal interaction.

\section{Discussion:}

In the present case, we observed the repercussion of the MTHFR gene polymorphism in the symptoms, signs, progression, and treatment of the patient with depressive disorder. There are several sites of MTHFR polymorphism reported, including 2 with the enzyme activity associated with the locus (C677T and A1298C) and 6 with enzyme activity that is not associated with the locus. ${ }^{3,7}$ The patient's genetic study revealed mutations in the two variants of the gene, with heterozygosis for C677T and A1298C. C677T variant results from a single nucleotide substitution in this position, in which cytosine is replaced by thymine, resulting in the conversion of alanine into valine residue. This substitution reduces the affinity of MTHFR and its cofactor, which promotes thermolability and decreases enzyme activity. In the A1298C mutation, adenine is replaced by cytosine, resulting in the conversion of glutamate into alanine in 429 residues, further contributing to the decrease in enzymatic activity. ${ }^{7}$ Heterozygosity can reduce the enzymatic action by about 30\%, while homozygosity in $60 \%$; if the patient has both variants, enzyme inactivity can reach $80 \% .^{3,7}$

MTHFR gene encodes the MTHFR enzyme, which catalyzes the reduction of 5,10methylenetetrahydrofolate to 5-methyltetrahydrofolate, its active form (popularly known as L-methylfolate). This gene mutation leads to a functional and non-quantitative deficiency of folate, because its conversion into the active form is impaired, maintaining normal serum levels. ${ }^{3}$ Partial inactivity of the enzyme MTHFR and, consequently, folate deficiency in its active form, leads to methylation defects, impairs the ideal function of essential metabolic pathways, including DNA synthesis and repair, neurotransmitter synthesis, gene regulation, protein function, antioxidant synthesis, heavy metal detoxification, immune activity, homocysteine regulation, and hormonal activity. $4,7,8$

Thus, MTHFR mutation can lead to a wide range of metabolic dysregulation, such as homocysteine accumulation, reduced methionine, and dysregulation of other pathways requiring methylation intermediates. ${ }^{4}$ There are many relevant studies on the connection between MTHFR polymorphism and human diseases, including cardiovascular diseases, tumors, neurological diseases, and psychiatric illnesses and disorders. ${ }^{2-4}$ Among psychiatric disorders, the relationship with depressive disorder is the best demonstrated.

One of the functions of L-methylfolate is to regulate $\mathrm{BH} 4$, cofactor of the reactions converting substrates into their respective monoamines (dopamine, noradrenaline, and serotonin). ${ }^{5}$ Low amounts of Lmethylfolate, regardless of whether they are due to genetic and/or environmental/dietary causes, could theoretically lead to low monoamine synthesis. Thus, their deficiency would be contributing to some patients' depression or refractoriness to treatment with antidepressants, because the mechanism of action of most of these drugs acts by inhibiting the monoamines receptors reuptake, which are unbalanced in 
depressive disorders; however, the problem in this case would be in its synthesis, not in its reception. ${ }^{3}$ This fact would explain the persistence of residual symptoms in the patient, even when he was treated with drugs with different mechanisms of action.

As the genetic polymorphism in the MTFHR gene leads to a reduction in the efficiency of methylation reactions (silencing), it ends up resulting in the accumulation of metabolic intermediates. When this is correlated with depression, it is important to take into account that hypomethylation of the gene encoding the enzyme COMT would lead to an increase in the activity of this enzyme that performs the degradation of dopamine and noradrenaline, which at low levels generate the pathophysiology of the depressive disorder. COMT in the periphery also metabolizes L-DOPA (precursor to dopamine and noradrenaline) in 3-Omethyldopa, which then competes with L-DOPA for uptake by the nervous system. ${ }^{3,8}$ This explains the patient's symptoms, which were, predominantly, a reduction in positive affect due to the lack of noradrenaline and dopamine.

Several recent studies demonstrating an increase in the frequency of folate deficiency among depressed patients, with more severe and prolonged depressive episodes and weaker response to treatment with antidepressants, also found an improved antidepressant response with folic acid supplementation; therefore, inadequate concomitant intake of folate and decreased MTHFR activity can be important factors of susceptibility to depression. $^{2}$

Because the administration of L-methylfolate has been effective as an adjuvant therapy for major depression resistant to selective serotonin reuptake inhibitors (SSRIs), and is approved by the Food and Drug Administration (FDA) as food supplement for patients with low folate levels and inadequate response to an antidepressant, oral replacement of this compound appears to be a promising alternative.,4

Individual MTHFR mutations, with partial or no response to SSRIs, respond well to L-methylfolate. According to a study published by Papakostas et.al (2012), there is a significant benefit with the dose of 15 $\mathrm{mg} /$ day, superimposed on the dose of $7.5 \mathrm{mg}$ /day, reaching the Necessary Number to Treat (NNT) equal to 6 - a very positive value if compared to the NNTs of several antidepressants ranging from 9 to 12 . In this study, it was also observed that $92 \%$ of patients achieved remission of symptoms within the first 6 months of therapy. $^{9}$

In Brazil, 15-mg doses are not yet commercially available, but there is the possibility of reaching this dose through formulations compounded in drops. In this case, the patient showed improvement of all residual symptoms with the supplementary administration of L-methylfolate $15 \mathrm{mg}$ and methyl B12 $750 \mathrm{mcg}$ - the latter, prescribed in case of an anemic condition from B12 deficiency not being masked by replacing folate.

\section{Conclusion:}

Folate (in the form of L-methylfolate) is a cofactor for the production of serotonin, dopamine, and noradrenaline synthesis rate-limiting enzymes. Moreover, it is also responsible for the "silencing" of the enzyme Catechol O-Methyltransferase (COMT), which degrades dopamine and noradrenaline. Its low serum level can result in a refractory response to conventional treatment in depression. Mutations in some specific alleles of MTHFR gene - especially C677T and A1298C - are known to negatively influence the action of folate in the body.

Methylfolate supplementation at a dosage of $15 \mathrm{mg} /$ day, as presented in the study by Papakostas et al, can contribute to the improvement of the depressive condition of $92 \%$ of patients with MTHFR mutation. ${ }^{9}$ Likewise, after supplementation at this dosage, the reported patient presented remission of depressive symptoms after 4 months of treatment. Improvement in the clinical picture is predominantly in the increase of positive affect, where noradrenaline and dopamine act.

The report of similar cases is extremely important to clarify this clinical condition and to find new treatment possibilities. In case of refractoriness in the treatment of depression, the search for MTHFR genetic mutation is important, allowing the investigation of the patient individually and, with this, indicating a more appropriate and effective treatment. 


\section{References:}

1. Jiang, W., Xu, J., Lu, X. J., \& Sun, Y. (2016). Association between MTHFR C677T polymorphism and depression: a meta-analysis in the Chinese population. Psychology, health \& medicine, 21(6), 675-685. https://doi.org/10.1080/13548506.2015.1120327

2. Jha, S., Kumar, P., Kumar, R., \& Das, A. (2016). Effectiveness of add-on l-methylfolate therapy in a complex psychiatric illness with MTHFR C677 T genetic polymorphism. Asian journal of psychiatry, 22, 74-75. https://doi.org/10.1016/j.ajp.2016.05.007

3. Do Prado CM, Dieckmann LHJ, Dieckmann PM. Farmacogenética na psiquiatria: entendendo os princípios e a aplicabilidade clínica. Rio de Janeiro: DOC Content; 2018.

4. Oberg, E., Givant, C., Fisk, B., Parikh, C., \& Bradley, R. (2015). Epigenetics in Clinical Practice: Characterizing Patient and Provider Experiences with MTHFR Polymorphisms and Methylfolate. Journal of nutrigenetics and nutrigenomics, 8(3), 137-150. https://doi.org/10.1159/000440700

5. Mech, A. W., \& Farah, A. (2016). Correlation of clinical response with homocysteine reduction during therapy with reduced B vitamins in patients with MDD who are positive for MTHFR C677T or A1298C polymorphism: a randomized, double-blind, placebo-controlled study. The Journal of clinical psychiatry, 77(5), 668-671. https://doi.org/10.4088/JCP.15m10166

6. Bjelland, I., Tell, G. S., Vollset, S. E., Refsum, H., \& Ueland, P. M. (2003). Folate, vitamin B12, homocysteine, and the MTHFR 677C->T polymorphism in anxiety and depression: the Hordaland Homocysteine Study. Archives of general psychiatry, 60(6), 618-626. https://doi.org/10.1001/archpsyc.60.6.618

7. Wan, L., Li, Y., Zhang, Z. et al. Methylenetetrahydrofolate reductase and psychiatric diseases. Transl Psychiatry 8, 242 (2018). https://doi.org/10.1038/s41398-018-0276-6

8. Gabriela Nielsen, M., Congiu, C., Bortolomasi, M., Bonvicini, C., Bignotti, S., Abate, M., Milanesi, E., Conca, A., Cattane, N., Tessari, E., Gennarelli, M., \& Minelli, A. (2015). MTHFR: Genetic variants, expression analysis and COMT interaction in major depressive disorder. Journal of affective disorders, 183, 179-186. https://doi.org/10.1016/j.jad.2015.05.003

9. Papakostas, G. I., Shelton, R. C., Zajecka, J. M., Etemad, B., Rickels, K., Clain, A., Baer, L., Dalton, E. D., Sacco, G. R., Schoenfeld, D., Pencina, M., Meisner, A., Bottiglieri, T., Nelson, E., Mischoulon, D., Alpert, J. E., Barbee, J. G., Zisook, S., \& Fava, M. (2012). L-methylfolate as adjunctive therapy for SSRI-resistant major depression: results of two randomized, double-blind, parallel-sequential trials. The American journal of psychiatry, 169(12), 1267-1274. https://doi.org/10.1176/appi.ajp.2012.11071114 